\title{
LEKSIKON EKOAGRARIS \\ DALAM BUDAYA PERTANIAN MASYARAKAT KECAMATAN SUMUR KABUPATEN PANDEGLANG
}

\section{ECOAGRARY LEXICON IN COMMUINITY AGRICULTURE CULTURE SUMUR DISTRICT, PANDEGLANG REGENCY}

\author{
Odien Rosidin; Asep Muhyidin \\ Program Studi Magister Pendidikan Bahasa Indonesia \\ Pascasarjana Universitas Sultan Ageng Tirtayasa \\ Jalan Raya Jakarta km 4, Pakupatan, Serang, Banten, Indonesia, 42118 \\ odienrosidin@untirta.ac.id
}
(Naskah diterima tangga 9 Agustus 2021, direvisi terakhir tanggal 4 November 2021, dan disetujui tanggal 22 Desember 2021)
DOI: https:/ / doi.org/10.26499/wdprw.v49i2.883

\begin{abstract}
The purpose of this study is to explain (1) the lexicon of the process of cultivating rice fields; (2) the process lexicon after harvesting rice; and (3) the lexicon of agricultural tools within the scope of agricultural culture in the Sumur sub-district community, Pandeglang district. This article is derived from the results of research with a descriptive qualitative approach using an ethnographic method based on ecolinguistic theory. Data were obtained from the results of participant observations and interviews with informants as many as 23 people who live in seven villages. The findings of this study are as follows: (1) the lexicon of the process of cultivating rice fields in the form of monomorphemic words; affixed polymorphemic words involving prefixes and confixes and reduplication results; and a combination of two words; (2) the process lexicon after harvesting rice in the form of affixed polymorphemic words involving prefixes and confixes; and a combination of two words; and (3) the lexicon of agricultural tools in the form of monomorphemic words; affixed polymorphemic words involving suffixes; and a combination of two words.
\end{abstract}

Keywords: lexicon; ecoagrarian; agriculture; Sunda

\begin{abstract}
Abstrak
Penelitian ini betujuan menjelaskan (1) leksikon proses penggarapan sawah; (2) leksikon proses setelah memanen padi; dan (3) leksikon alat-alat pertanian dalam lingkup budaya pertanian di lingkungan masyarakat Kecamatan Sumur, Kabupaten Pandeglang. Artikel ini berasal dari hasil penelitian dengan pendekatan kualitatif deskriptif berdasarkan ancangan metode etnografis yang berbasis pada teori ekolinguistik. Data diperoleh dari hasil observasi partisipan dan wawancara kepada informan sebanyak 23 orang yang berdomisili di tujuh desa. Penelitian ini menghasilkan tiga temuan. Pertama, leksikon proses penggarapan sawah berupa kata monomorfemis; kata polimorfemis hasil afiksasi yang melibatkan prefiks dan konfiks atau reduplikasi; serta gabungan dua kata. Ketiga, leksikon proses setelah memanen padi berupa kata polimorfemis hasil afiksasi yang melibatkan prefiks dan konfiks serta gabungan dua kata. Ketiga, leksikon alat-alat pertanian berupa kata monomorfemis; kata polimorfemis hasil afiksasi yang melibatkan sufiks dan gabungan dua kata.
\end{abstract}

Kata-kata kunci: leksikon; ekoagraris; agrikultur; Sunda 


\section{Pendahuluan}

Dalam upaya memenuhi tuntutan dan kebutuhan hidup, manusia merekayasa alam dan sosial dengan menggunakan peralatan canggih. Manusia mengolah lingkungan fisik alam semesta dan biologis (Susilo, 2008: 54; Chang, 2001: 16; Nuzwaty, 2019: 14). Terjadinya ledakan populasi penduduk dunia berdampak pada tekanan yang tinggi terhadap lingkungan. Kebutuhan terhadap pakaian, makanan, dan tempat tinggal memberi desakan yang kuat pada daya dukung lahan yang terbatas (Hidayati dan Soeprobowati, 2017: 126).

Isu lingkungan kian menjadi per-sonalan sentral bagi masyarakat dunia. Lingkungan bukan permasalahan tunggal karena bergayutan dengan pelbagai bidang kehidupan. Oleh sebab itu, lingkungan atau ekologi menjadi permasalahan bersama umat manusia karena mengimplikasikan relasi timbal balik. Manusia dan lingkungan terusmenerus berinteraksi dan saling bergantung untuk keberlangsungan keduanya (Odum, 1996: 3-5; Ndruru, 2020: 257). Hal utama yang menjadi konsep kunci di dalam ekologi adalah ekosistem (Fill, 2018: 149).

Entitas dalam suatu lingkungan dicirikan oleh bahasa sehingga tiap-tiap bahasa merepresentasikan perbedaan entitas lingkungan. yang dimiliki (Sinaga, Simpen, dan Satyawati, 2021: 1). Relasi manusia dan alam menghasilkan keragaman bahasa. Dalam hal itu, lingkungan budaya berkait erat dengan kualitas dan kondisi hidup kebahasaan. Menurut Suktiningsih (2016: 134), kajian ekolinguistik diperlukan dalam rangka mengkaji hubungan dwiarah antara lingkungan alam dan bahasa.

Ekolinguistik dapat diposisikan seba-gai studi kritis yang termasuk cabang linguistik terapan dengan pengkhususan pada studi bahasa dan krisis lingkungan (Dash, 2019: 379). Ekolinguistik mempelajari bahasa menurut lingkungan tempatnya digunakan
(Derni, 2008: 22). Pendekatan teori ekolinguistik dipakai untuk mengkaji permasalahan yang berhubungan dengan lingkungan, termasuk leksikon ekoagraris dalam lingkup budaya suatu masyarakat.

Leksikon ekoagraris yang dimiliki oleh suatu masyarakat bahasa merepresen-tasikan nilai budaya dan kearifan ekologi lokal yang berhubungan dengan pengolahan sumber daya alam untuk pemenuhan kebu-tuhan hidup. Sejalan dengan itu, leksikon merupakan komponen bahasa yang memuat semua informasi tentang makna dan pema-kaian kata dalam bahasa (Kridalaksana, 2008: 142). Leksikon merupakan komponen yang mengandung informasi tentang ciri-ciri kata dalam suatu bahasa, antara lain perilaku semantik, sintaksis, dan fonologis (Crystal, 1985: 78)

Keberadaan leksikon ekoagraris dalam suatu masyarakat budaya menarik dan penting dikaji, termasuk sistem dan budaya pertanian masyarakat Sunda di wilayah Kecamatan Sumur, Kabupaten Pandeglang, Provinsi Banten. Masyarakat di wilayah itu memiliki keunikan bahasa dan budaya tersendiri, yang berbeda dengan penutur bahasa Sunda di tempat lain, baik di Kabupaten Pandeglang maupun di kabupaten/kota lainnya di Provinsi Banten. Perbedaan itu tampak dalam khazanah kosakata budaya yang mereka miliki yang bersifat khas dan unik sehingga berbeda dengan komunitas masyarakat Sunda lainnya yang berada di Kabupaten/Kota Serang, Kabupaten Pandeglang, Kabupaten/ Kota Tangerang, Kota Tangerang Selatan, dan Kabupaten Lebak.

Artikel ini terpumpun pada leksikon ekoagraris dalam budaya pertanian masyarakat tutur bahasa Sunda di wilayah Kecamatan Sumur. Lokasi penelitian ini meliputi satu wilayah, yakni Kecamatan Sumur. Adapun lokus penelitian ini ialah kampung-kampung yang berada di wilayah 
desa yang termasuk Kecamatan Sumur. Artikel ini menjawab rumusan masalah (1) apa sajakah leksikon proses penggarapan sawah yang dilakukan oleh masyarakat petani di wilayah Kecamatan Sumur, Kabupaten Pandeglang; (2) apa sajakah leksikon proses pascatanam padi yang dilakukan oleh masyarakat petani di wilayah Kecamatan Sumur, Kabupaten Pandeglang; dan (3) apa sajakah leksikon alat-alat pertanian yang digunakan oleh masyarakat petani di wilayah Kecamatan Sumur, Kabupaten Pandeglang? Sejalan dengan rumusan masalah tersebut, penelitian ini bertujuan untuk menjelaskan (1) leksikon proses penggarapan sawah yang dilakukan oleh masyarakat petani di wilayah Kecamatan Sumur, Kabupaten Pandeglang; (2) leksikon proses setelah memanen padi yang dilakukan oleh masyarakat petani di wilayah Kecamatan Sumur, Kabupaten Pandeglang; dan (3) leksikon alat-alat pertanian yang digunakan oleh masyarakat petani di wilayah Kecamatan Sumur, Kabupaten Pandeglang.

Berdasarkan hasil pencarian penulis, ditemukan beberapa penelitian yang mengkaji leksikon ekoagraris dan leksikon pertanian dalam beberapa bahasa dan budaya di Indonesia. Wisudariani (2015) melakukan penelitian "Khazanah Kosakata dan Pergeseran Kosakata dalam Sistem Pertanian Tradisional". Hasil penelitian ini berupa ditemukannya kosakata sistem pertanian tradisional yang bergeser penggunaannya karena diberlakukannya sistem pertanian modern. Hal itu tidak dapat dipisahkan dari perubahan lingkungan, aktivitas pertanian, dan peralatan yang digunakan.

Kesuma dan Nurlela (2015) melakukan penelitian "Keterancaman Leksikon Ekoagraris dalam Bahasa Angkola/Mandailing: Kajian Ekolinguistik". Hasil dan temuan penelitian ini ialah (1) leksikon bagian sawah; (2) leksikon benda-benda persawahan dan perladangan; (3) leksikon peralatan produksi hasil panen; (4) leksikon alur beras dan palawija; (5) leksikon alat dan mesin pertanian; (6) leksikon tumbuhan sawah dan sekitar sawah; (7) leksikon tanaman ladang; (8) leksikon nama tumbuhan obat di sekitar sawah dan ladang; (9) leksikon fauna dalam persawahan dan perladangan; (10) leksikon alat penangkap ikan; dan (11) leksikon alat penangkap burung.

Penelitian lain dilakukan oleh Tualaka (2016) dengan judul "Bentuk Khazanah Ekoleksikon Pertanian Bahasa Waijewa". Penelitian ini berhasil mendeskripsikan bentuk ekoleksikon pertanian dalam bahasa Waijewa yang dapat diklasifikasikan menjadi nomina, verba, dan adjektiva.

Sementara itu, Sari (2020) meneliti "Berkebun Sayur Bersama Masyarakat Nias: Studi Ekolinguistik dari Sebuah Kepulauan." Penelitian ini memperoleh temuan berupa 25 leksikon sayur di kebun masyarakat Nias. Leksikon tersebut dikategorikan sebagai nomina. Berdasarkan bentuk gramatikalnya, terdapat 16 leksikon berupa kata dasar dan 9 leksikon berupa kata turunan.

Dengan demikian, penelitian tentang leksikon ekoagraris dalam lingkup budaya pertanian yang berpijak pada pendekatan ekolinguistik di wilayah Kecamatan Sumur belum pernah ada yang melakukan. Penelitian ini diharapkan dapat mengisi kerumpangan tersebut sekaligus menghasilkan temuan yang dapat melengkapi hasil penelitian tentang khazanah leksikon pertanian dalam lingkup budaya masyarakat Sunda.

Dengan menggunakan ancangan teori ekolinguistik, dimensi keterkaitan bahasa dan ekologi yang diungkapkan melalui leksikon ekoagraris dapat dieksplanasikan dengan tujuan-tujuan konservasi budaya. Menurut Yuniawan, Masrukhi, dan Alamsyah (2014: 42), konservasi bukan sekadar berhubungan dengan proses menjaga, 
merawat, dan melestarikan lingkungan alam, tetapi juga kebudayaan atau peradaban manusianya. Konservasi bukan semata tindakan menjaga atau memelihara lingkungan alam (fisik), tetapi juga nilai dan kreasi budaya manusia yang perlu dipelihara, diapresiasi, serta dirawat keberlangsungannya demi kepentingan hidup manusia yang lebih baik (Handoyo dan Tijan, 2010: 16; Yuniawan, Masrukhi, dan Alamsyah, 2014: 42).

Hubungan bahasa dan lingkungan direfleksikan oleh peristilahan unsur bahasa, sistem bunyi, dan makna kata. Keterikatan itu tampak pada tingkat kosakata. Bagi suatu bahasa, kosakata secara total merepresentasikan ciri dan keunikan lingkungan fisik dan budaya masyarakat pendukungnya. Oleh sebab itu, bahasa dan lingkungan membentuk suatu sistem (Juwitasari dan Kristianto, 2020). Ekolinguistik memosisikan sumber daya manusia dan budaya berkenaan dengan lingkungan alam yang dilambangkan secara verbal melalui bahasa. Ekolinguistik mengkaji hubungan bahasa dengan lingkungan alam atau sosial, termasuk simbolsimbol bahasa dan budaya yang menggambarkan kausalitas simbolis verbal antara manusia dan manusia, manusia dan tuhan, serta manusia dan alam sekitarnya (Tualaka, 2016: 106). Berdasarkan pendapat-pendapat tersebut, leksikon dalam artikel ini berupa kata-kata dan rujukannya dalam bidang ekoagraris yang merepresentasikan budaya pertanian masyarakat penutur jati bahasa Sunda di lingkungan Kecamatan Sumur.

\section{Metode}

Penelitian ini memanfaatkan rancangan penelitian deskriptif kualitatif dengan memakai metode etnografis yang berbasis pada teori ekolinguistik. Data diperoleh melalui observasi partisipan di lapangan dan hasil wawancara kepada informan pada April, Mei, dan Juni 2021 di perkampungan atau perdesaan yang termasuk wilayah Kecamatan Sumur, Kabupaten Pandeglang. Informan penelitian ini sebanyak 23 orang, yakni warga masyarakat yang sehari-hari bekerja sebagai petani di sawah, kebun, atau ladang yang dianggap memahami dan menguasai masalah pertanian, baik dari segi teknis maupun sosial dan budaya. Berdasarkan sebaran domisilinya, informan tersebut diperinci sebagai sebagai berikut: (1) informan yang berdomisili di Desa Tunggaljaya sebanyak 3 orang; (2) informan yang berdomisili di Desa Sumberjaya sebanyak 3 orang; (3) informan yang berdomisili di Desa Cigorondong sebanyak 3 orang, (4) informan yang berdomisili di Desa Kertamukti sebanyak 3 orang, (5) informan yang berdomisili di Desa Tamanjaya sebanyak 3 orang, (6) informan yang berdomisili di Desa Kertajaya sebanyak 4 orang, dan informan yang berdomisili di Desa Ujung Jaya sebanyak 4 orang. Teknik analisis data dilakukan dengan menggunakan model interaktif Miles dan Huberman (1992: 20). Sejalan dengan itu, analisis data penelitian ini dilakukan melalui empat tahapan, yaitu (1) pengumpulan data penelitian; (2) reduksi data penelitian; (3) penyajian data penelitian, dan (4) verifikasi.

\section{Hasil dan Pembahasan}

Berikut ini dipaparkan hasil analisis dan pembahasan temuan leksikon ekoagraris dalam lingkup budaya pertanian masyarakat Kecamatan Sumur, Kabupaten Pandeglang.

\subsection{Leksikon Nama Proses Penggarapan Sawah}

Bagian ini berisi tentang bentuk satuan kebahasaan leksikon nama proses penggarapan sawah yang dilakukan oleh masyarakat petani di wilayah Kecamatan Sumur, Kabupaten Pandeglang. Bentuk satuan kebahasaan tersebut berupa kata mono- 
morfemis, polimorfemis, dan gabungan dua kata.

\subsubsection{Leksikon Nama Proses Penggarapan Sawah Berupa Kata Monomorfemis}

Dalam lingkup budaya pertanian masyarakat Kecamatan Sumur ditemukan leksikon penamaan proses penggarapan sawah berupa kata monomorfemis atau kata yang terdiri atas satu morfem berikut ini:

(1) babut

Kata babut memiliki arti 'mencabut benih padi'. Kata ini menunjukkan proses petani mencabut benih padi yang disemai untuk kemudian ditanam.

(2) mipit

Kata mipit memiliki arti 'memetik/ memanen'. Kata ini menunjukkan proses petani memanen padi yang sudah siap dipetik.

(3) mulihan

Kata mulihan memiliki arti 'membereskan atau menyelesaikan panen yang tertunda'. Kata ini menunjukkan proses yang dilakukan petani untuk menyelesaikan pemanenan padi.

(4) nukuh

Kata nukuh memiliki arti 'melakukan ritual adat/tradisi'. Kata ini menunjukkan proses melakukan upacara atau ritual adat yang terkait dengan aktivitas bertani, baik sebelum bersawah maupun setelah panen.

(5) panen

Kata panen memiliki arti 'memetik hasil'. Kata ini menunjukkan proses yang dilakukan petani untuk memanen padi yang sudah siap dipanen/matang.

(6) singkal

Kata singkal memiliki arti 'membajak dengan alat bajak dari kayu'. Kata ini menunjukkan proses yang dilakukan petani untuk melakukan pembajakan sawah sebelum proses tanam padi dimulai.

(7) tandur
Kata tandur memiliki arti 'menanam benih padi'. Kata ini menunjukkan proses yang dilakukan petani untuk menanam benih padi yang sudah disiapkan.

\subsubsection{Leksikon Nama Proses Penggarapan Sawah Berupa Kata Polimorfemis}

Dalam penelitian leksikon ekoagraris dalam lingkup budaya pertanian masyarakat Kecamatan Sumur ditemukan leksikon berupa kata yang secara morfologis dihasilkan dari proses afiksasi dan reduplikasi. Berikut ini merupakan leksikon proses penggarapan sawah yang dibentuk dari afiksasi berupa pembubuhan prefiks dan konfiks pada kata dasar.

\subsubsection{Prefiks $d i$ -}

Prefiks di- yang dibubuhkan pada kata dasar berkategori verba menghasilkan leksikon verba pasif yang menunjukkan proses, yaitu (a) dialus 'dihaluskan'; (b) dicaplak 'diberi ukuran/garis'; (c) dietem 'dipanen/dipetik'; (d) digaleng 'dibuatkan pematang'; (e) digebot 'dipanen'; (f) digowo 'diberi jarak'; (g) dikuber 'dipotong rumputnya'; (h) dileler 'dilubangi'; (i) dioyos 'dibersihkan'; (j) dipacul 'dicangkul'; (k) dipeuyeum 'diperam'; (l) dipupuk 'diberi pupuk'; (m) diramas 'disiangi'; dan (n) ditaplak 'diberi ukuran'.

\subsubsection{Prefiks nga-}

Prefiks nga- yang dibubuhkan pada kata dasar berkategori verba menghasilkan leksikon verba aktif yang menunjukkan proses, yaitu (a) ngagaru 'membajak'; (b) ngagasrok 'membersihkan rumput dengan alat'; (c) ngagebot 'memanen'; (d) ngagowo 'memberi jarak'; (e) ngalektor 'membajak dengan traktor'; (f) ngarabut 'mencabut benih padi'; (g) ngararata 'meratakan'; (h) ngarit 'memotong rumput dengan sabit'; (i) ngaseuk 'melubangi tanah dengan kayu'; dan (j) ngawiluku 'membajak sawah'. 


\subsubsection{Prefiks $n g$ -}

Prefiks $n g$-yang dibubuhkan pada kata dasar berkategori verba menghasilkan leksikon verba aktif yang menunjukkan proses, yaitu (a) ngobat 'meracun hama'; (b) ngorea 'memberi pupuk urea'; (c) ngoyos 'membersihkan rumput di sela-sela padi'; dan (d) nguber 'mengobok-obok'.

\subsubsection{Prefiks $n y$ -}

Prefiks $n y$ - yang dibubuhkan pada kata dasar berkategori verba menghasilkan leksikon verba aktif yang menunjukkan proses, yaitu (a) nyacar 'membersihkan rumput'; (b) nyalampak 'memberi garis sawah atau ukuran untuk menanam benih'; (c) nyaplak 'memberi garis atau ukuran saat menanam benih'; (d) nyebar 'menabur atau menyemai benih'; dan (e) nyemprot 'memberi racun untuk hama'.

\subsubsection{Prefiks m-}

Prefiks $m$ - yang dibubuhkan pada kata dasar berkategori verba menghasilkan leksikon verba aktif yang menunjukkan proses, yaitu (a) mabal 'membersihkan rumput' dan (b) mupuk'memberi pupuk supaya subur'.

\subsubsection{Konfikes $d i-+-a n$}

Konfiks di- + -an yang dibubuhkan pada kata dasar nomina menghasilkan verba pasif yang menunjukkan proses, yaitu digarisan 'diberi ukuran'.

Untuk leksikon proses penggarapan sawah yang dibentuk dari proses morfologis berjenis reduplikasi hanya ditemukan satu data, yakni pengulangan suku depan dari kata galeng yang menghasilkan bentuk gagaleng 'membuat batas sawah atau jalan di sawah'. Kata ini menunjukkan proses yang dilakukan petani dalam membuat pematang sawah yang biasanya difungsikan sebagai batas dan jalan.

\subsubsection{Leksikon Nama Proses Penggarapan Sawah Berupa Gabungan Kata}

Dalam penelitian leksikon ekoagraris dalam lingkup budaya pertanian masyarakat Kecamatan Sumur ditemukan leksikon yang merupakan gabungan dua kata. Berikut ini merupakan leksikon proses penggarapan sawah yang dibentuk dari gabungan dua kata.

(8) babal galeng

Gabungan dua kata tersebut menghasilkan arti 'membersihkan batas sawah atau jalan di sawah'.

(9) digaruk kebo

Gabungan dua kata tersebut menghasilkan arti 'dibajak oleh kerbau'.

(10) macul galeng

Gabungan dua kata tersebut menghasilkan arti 'mencangkul atau merapikan batas sawah'.

(11) mupuk buah

Gabungan dua kata tersebut menghasilkan arti 'memberi pupuk untuk buah'.

(12) mupuk dasar

Gabungan dua kata tersebut menghasilkan arti 'memberi pupuk sebelum lahan ditanami padi'.

(13) mupukpare

Gabungan dua kata tersebut menghasilkan arti 'memupuk padi'.

(14) namping galeng

Gabungan dua kata tersebut menghasilkan arti 'membersihkan batas sawah atau jalan sawah'.

(15) naplok galengan

Gabungan dua kata tersebut menghasilkan arti 'menambah pematang dengan lumpur sawah'.

(16) ngalektor alus

Gabungan dua kata tersebut menghasilkan arti 'membajak sawah untuk yang kedua kali supaya lumpur lebih lembut'.

(17) ngeueum binih

Gabungan dua tersebut menghasilkan arti 'merendam padi'. 


\section{(18) nyabut binih}

Gabungan dua kata tersebut menghasilkan arti 'mencabut benih padi'.

(19) nyaian sawah

Gabungan dua kata tersebut menghasilkan arti 'mengairi sawah'.

(20) nyebar binih

Gabungan dua kata tersebut menghasilkan arti 'menabur atau menyemai benih padi'.

\section{(21) nyieun panyebaran}

Gabungan dua kata tersebut menghasilkan arti 'membuat tempat penyemaian'.

Keseluruhan leksikon yang ditemukan tersebut mencerminkan tradisi pertanian sebagai praktik budaya yang diwarisi dari generasi terdahulu atau leluhur masyarakat Kecamatan Sumur. Hal itu sejalan pernyataan Baehaqie (2014: 181) bahwa terdapat hubungan yang erat antara leksikon bahasa dan kehidupan masyarakat penuturnya (Baehaqie, 2014: 181). Dalam hal ini, menurut Sahril (2020: 150) lingkungan ragawi dan sosial berhubungan dengan perangkat leksikon yang menunjukkan adanya hubungan simbolik verbal guyub tutur dan lingkungannya, flora dan fauna, termasuk unsurunsur alamiah lainnya.

Temuan di atas diperkuat oleh pernyataan Nurhayati (2010: 41) bahwa perangkat pengetahuan dan keterampilan terkait tata cara pengolahan tanah sampai dengan bertanam padi dikuasai secara bersama oleh petani tradisional. Pengetahuan dan keterampilan itu diperoleh sebagai tinggalan turuntemurun. Teknik membagi-bagi proses dan tahap pengolahan tanah tersebut dipengaruhi oleh kosakata (bahasa) yang dimiliki.

Sementara itu, Wahya, Djajasudarma, dan Citraresmana (2017: 209) menyatakan bahwa proses bertanam padi di sawah mengandungi nilai-nilai tradisi karena menunjuk-kan tahapan yang detail mulai dari pengolahan lahan sampai dengan memanen padi. Dalam lingkup masyarakat yang bermatapencarian sebagai petani di sawah, termasuk masyarakat Sunda, bertanam padi bukan semata pekerjaan perseorangan, tetapi juga melibatkan orang dengan keahlian masing-masing pada tahapan tertentu yang dibutuhkan.

Proses bertanam padi di sawah menunjukkan adanya ikatan dan proses kohesi sosial sebagai cerminan keguyuban, gotong-royong, dan kerja keras. Sejalan dengan pernyataan itu, aktivitas bertanam padi yang dilakukan oleh masyarakat di Kecamatan Sumur juga menunjukkan adanya keikutsertaan orang lain. Hal itu terlihat, misalnya, melalui leksikon ngagebot, mipit, dan ngoyos. Aktivitas-aktivitas yang merupakan tahapan dalam bertanam padi tersebut dikerjakan secara bergotong royong dan menjadi tradisi bagi masyarakat setempat.

Meskipun demikian, sebagaimana terjadi pada masyarakat agraris lainnya, tradisi pertanian di wilayah Kecamatan Sumur juga mendapat pengaruh dari sistem pertanian modern. Hal itu tampak dari ditemukannya tiga buah leksikon yang menunjukkan terjadinya transformasi sistem pertanian dari tradisional ke modern. Pertama, terkait dengan penggunaan mesin traktor yang terungkap melalui leksikon ngalektor. Dalam hal ini, sistem pembajakan sawah dengan pembajak tradisional mulai tergeser dengan alat modern. Kedua, terkait dengan penggunaan pestisida yang disemprotkan pada tanaman (padi) untuk membasmi hama yang terungkap melalui leksikon nyemprot. Dalam hal ini, proses penyemprotan dilakukan dengan cara menyemprotkan bahan kimia sebagai produk pertanian modern yang difungsikan untuk membasmi hama. Ketiga, terkait dengan penggunaan pupuk urea untuk menyuburkan tanah yang ditunjukkan oleh leksikon ngorea. Dalam hal ini, penggunaan urea menggantikan pupuk 
alami yang sebelumnya digunakan sebagai bahan penyubur tanah dan tanaman.

\subsection{Leksikon Nama Proses Setelah Memanen Padi}

Bagian ini berisi bentuk satuan kebahasaan leksikon nama proses setelah memanen padi yang dilakukan oleh masyarakat petani di wilayah Kecamatan Sumur. Bentuk satuan kebahasaan tersebut berupa kata polimorfemis dan gabungan dua kata.

\subsubsection{Leksikon Nama Proses Setelah Memanen Padi Berupa Kata Polimorfemis}

Dalam penelitian leksikon ekoagraris dalam lingkup budaya pertanian masyarakat Kecamatan Sumur ditemukan leksikon proses setelah memanen padi berupa kata yang secara morfologis dihasilkan dari proses afiksasi. Berikut ini merupakan leksikon proses setelah memanen padi yang dibentuk dari afiksasi berupa pembubuhan prefiks dan konfiks pada kata dasar.

\subsubsection{Prefiks $d i$ -}

Prefiks di- yang dibubuhkan pada kata dasar berkategori verba menghasilkan leksikon verba pasif yang menunjukkan proses, yaitu (a) dibawa yang memiliki arti 'dibawa dari sawah ke rumah'; (b) diganggang yang memiliki arti 'dijemur di atas penjemur yang terbuat dari bambu'; (c) digantung yang memiliki arti 'disimpan dengan cara digantung'; (d) digiling yang memiliki arti 'diproses menjadi beras dengan menggunakan mesin penggiling;; (e) dihuru yang memiliki arti 'dibakar', yaitu proses membakar jerami padi atau rumput; (f) dipoe yang memiliki arti 'dijemur'; (g) diselip yang memiliki arti 'digiling dengan mesin agar menjadi beras'; (h) ditapi yang memiliki arti 'ditampi agar terpisah/bersih dari kotoran atau gabah'; (i) ditutu yang memiliki arti 'ditumbuk dengan alat tradisional/penumbuk padi agar menjadi beras'.

\subsubsection{Prefiks $m$ -}

Prefiks $m$ - yang dibubuhkan pada kata dasar berkategori verba menghasilkan leksikon verba aktif yang menunjukkan proses, yaitu moe. Leksikon ini menunjukkan proses menjemur gabah agar menjadi kering sehingga siap untuk diproses menjadi beras, baik digiling (dengan mesin) atau ditutu 'ditumbuk' dengan alat tradisional.

\subsubsection{Prefiks nga-}

Prefiks nga- yang dibubuhkan pada kata dasar berkategori verba menghasilkan leksikon verba aktif yang menunjukkan proses, yaitu (a) ngagiling yang memiliki arti 'menggiling gabah menjadi beras yang siap dikonsumsi' dan (b) ngahuru yang memiliki arti 'membakar rumput'.

\subsubsection{Prefiks $n g$ -}

Prefiks ng- yang dibubuhkan pada kata dasar berkategori verba menghasilkan leksikon verba aktif yang menunjukkan proses, yaitu ngunjal yang memiliki arti 'mengangkut'. Leksikon ini menunjukkan proses mengangkut padi dari sawah ke rumah'.

\subsubsection{Prefiks $n$ -}

Prefiks $n$ - yang dibubuhkan pada kata dasar berkategori verba menghasilkan leksikon verba aktif yang menunjukkan proses, yaitu nutu yang memiliki arti 'menumbuk dengan penumbuk atau alat tradisional, yaitu alu dan lesung'.

\subsubsection{Konfiks $n g a-+-a n$}

Konfiks nga- + -an yang dibubuhkan pada kata dasar berkategori adjektiva menghasilkan leksikon verba aktif yang menunjukkan proses, yaitu nganyaran yang memiliki arti 'memperbarui'.

\subsubsection{Konfiks di- + -an}

Konfiks di- + -an yang dibubuhkan pada kata dasar berkategori nomina menghasilkan 
leksikon verba pasif yang menunjukkan proses, yaitu dikarungan yang memiliki arti 'dimasukkan ke dalam karung' dan yang dibubuhkan pada kata dasar berkategori verba menghasilkan leksikon verba pasif yang menunjukkan proses, yaitu dilanaian yang memiliki arti 'dijemur di tempat penjemuran padi'.

\subsubsection{Konfiks di- + -keun}

Konfiks di- + -keun yang dibubuhkan pada kata dasar berkategori adjektiva menghasilkan leksikon verba aktif yang menunjukkan proses, yaitu digaringkeun yang memiliki arti 'dikeringkan dengan cara dijemur'. Leksikon proses ini memiliki kesamaan dengan leksikon moe, dipoe, dan dilanaian, serta diganggang karena menunjukkan proses pengeringan padi dengan cara dijemur langsung di bawah panas matahari.

\subsubsection{Leksikon Nama Proses Setelah Memanen Padi Berupa Gabungan Kata}

Dalam penelitian leksikon ekoagraris dalam lingkup budaya pertanian masyarakat Kecamatan Sumur ditemukan leksikon berupa gabungan dari dua kata. Berikut ini merupakan leksikon proses setelah memanen padi yang dibentuk dari gabungan dua kata. (22) moe gabah

Gabungan dua kata tersebut menghasilkan arti 'menjemur padi dengan memanfaatkan panas matahari sehingga kering dan siap diolah/dikonsumsi'.

(23) ngingkeun saminggu

Gabungan dua kata tersebut menghasilkan arti 'membiarkan selama seminggu'.

Keseluruhan gabungan kata tersebut menunjukkan aktivitas yang dilakukan oleh petani setelah memanen padi, baik proses mengolah padi sampai siap dikonsumsi maupun proses mengolah sawah pascapanen untuk kepentingan proses bercocok tanam berikutnya.
Temuan tersebut menunjukkan bahwa dalam proses mengolah padi setelah dipanen, terdapat leksikon yang menunjukkan proses yang masih bersifat tradisional karena dilakukan secara sederhana dan sesuai dengan kebiasaan yang mereka warisi dari generasi sebelumnya, seperti diungkapkan dengan leksikon moe, ditapi, dan nutu. Namun, terdapat pula leksikon yang menunjukkan masuknya pengaruh kehidupan modern, seperti tampak dalam leksikon ngagiling, yakni menggiling gabah/padi dengan mesin penggiling.

Temuan leksikon proses setelah memanen padi tersebut sejalan dengan pendapat Budhiono (2017: 236) bahwa suatu istilah menghadirkan konsep tertentu yang lekat dipengaruhi oleh faktor budaya masyarakat pemiliknya. Tentu saja tidak sekadar benda, melainkan juga aktivitas dalam kehidupan. Jika merupakan kegiatan atau bagian dari mata pencarian utama, setiap proses dan fase aktivitasnya diwadahi serta dihadirkan dengan istilah tertentu. Oleh karena itu, menurut Wahyuni (2017: 22) istilah dalam lingkup ranah pertanian harus diposisikan maknanya dari aspek leksikal dan kultural.

Leksikon proses setelah memanen padi yang ditemukan di wilayah Kecamatan Sumur bukan sekadar tata nama atau penyebutan aktivitas bertani, tetapi juga memiliki kandungan nilai yang merepresentasikan budaya masyarakat dalam keseharian hidup mereka.

\subsection{Leksikon Nama Alat-alat Pertanian}

Bagian ini berisi tentang bentuk satuan kebahasaan leksikon nama alat pertanian dalam lingkup budaya pertanian masyarakat Kecamatan Sumur. Bentuk satuan kebahasaan tersebut berupa kata monomorfemis, kata polimorfemis, dan gabungan dari dua kata. 


\subsubsection{Leksikon Nama Alat-alat Pertanian Berupa Kata Monomorfemis}

Dalam lingkup budaya pertanian masyarakat Kecamatan Sumur ditemukan leksikon alat pertanian yang terdiri atas satu morfem. Berikut ini merupakan leksikon alat pertanian berupa kata monomorfemis.

(24) ajir

Kata ajir memiliki arti 'patok dari kayu'.

(25) arit

Kata arit memiliki arti 'sabit'.

(26) aseuk

Kata aseuk memiliki arti 'alat melubangi tanah yang terbuat dari kayu'.

(27) balencong

Kata balencong memiliki arti 'belencong'.

(28) bedog

Kata bedog memiliki arti 'golok'.

(29) caluk

Kata caluk memiliki arti 'congkrang'.

(30) caplak

Kata caplak memiliki arti 'alat penggaris/ pemberi ukuran menanam padi'.

(31) etem

Kata etem memiliki arti 'ani-ani/pisau pemotong padi dan bambu yang saling menyilang dengan pisau kecil yang ditancapkan pada muka kayu'.

(32) garpuh

Kata garpuh memiliki arti 'garpu'.

(33) garu

Kata garu memiliki arti 'alat pembajak sawah'.

(34) gasrok

Kata gasrok memiliki arti 'alat untuk menggaruk tanah'.

(35) lisung

Kata lisung memiliki arti 'lumpang kayu panjang'.

(36) rengkong

Kata rengkong memiliki arti 'alat yang terbuat dari bambu dan tali'.

\subsubsection{Leksikon Nama Alat-alat Pertanian Berupa Kata Polimorfemis}

Dalam penelitian leksikon ekoagraris dalam lingkup budaya pertanian masyarakat Kecamatan Sumur ditemukan leksikon alat pertanian berupa kata yang secara morfologis dihasilkan dari proses afiksasi. Berikut ini merupakan leksikon alat pertanian yang dibentuk dari afiksasi berupa pembubuhan sufiks -an pada kata dasar.

Sufiks -an yang dibubuhkan pada kata dasar berkategori nomina menghasilkan leksikon yang menunjukkan makna alat untuk melakukan suatu pekerjaan yang berhubungan dengan proses bertani, yaitu (a) caplakan yang memiliki arti 'alat penggaris atau pemberi ukuran menanam padi'; (b) gasrokan yang memiliki arti 'alat untuk menggaruk tanah'; dan (c) gebotan yang memiliki arti 'alat untuk memanen padi'.

\subsubsection{Leksikon Nama Alat-alat Pertanian Berupa Gabungan Kata}

Dalam penelitian leksikon ekoagraris dalam lingkup budaya pertanian. masyarakat Kecamatan Sumur ditemukan leksikon alat pertanian berupa gabungan dua kata. Berikut ini merupakan leksikon proses penggarapan sawah yang dibentuk dari gabungan dua kata.

(37) garu kebo

Gabungan dua kata tersebut menghasilkan arti 'alat untuk membajak sawah dengan bantuan kerbau'.

(38) perah bedog

Gabungan dua kata tersebut menghasilkan arti 'pegangan golok'.

Leksikon-leksikon yang ditemukan tersebut menunjukkan penamaan alat-alat bertani yang khas dalam bahasa Sunda di wilayah Kecamatan Sumur. Berdasarkan acuan bentuk dan fungsinya, mungkin saja alat-alat pertanian tersebut memiliki kesamaan dengan alat pertanian yang digunakan di tempat lain. Atau, hanya berbeda 
penamaannya. Hal itu sejalan dengan pendapat Prayitno \& Arsyad (2009: 127) bahwa peralatan pertanian padi tradisional dalam masyarakat Jawa lazimnya menunjukkan kesamaan. Namun, tentu akan ditemukan perbedaan, terutama pemberian nama antara satu daerah dan daerah lainnya (Lestari, Irawati, dan Mujimin, 2019: 3). Perbedaan itu menampakkan wujud budaya yang menjadi penciri khas bagi setiap komunitas. Hal itu senada dengan pernyataan Santoso (2018: 378) bahwa leksikon kebahasaan mendapat pengaruh dari lingkungan tempat bahasa tersebut bereksistensi. Selanjutnya, dinyatakan oleh Sinaga, Simpen, dan Satyawati (2021: 2) bahwa manusia yang menempati lingkungan tertentu akan lebih memahami secara utuh bagian dan unsur lingkungan itu sebagaimana teridentifikasi melalui bahasa yang dituturkan

Terdapat beberapa alat pertanian yang umumnya dibuat sendiri oleh warga masyarakat yang bermata pencarian sebagai petani di Kecamatan Sumur, yaitu aseuk dibuat dari kayu; caplakan dibuat dari kayu; gagang arit dibuat dari kayu; gagang balencong dibuat dari kayu; gagang kored dibuat dari kayu; gagang pacul dibuat dari kayu; garoban dibuat dari kayu; garokan dibuat dari kayu; garu dibuat dari kayu; gebotan dibuat dari kayu atau bambu; lanaian dibuat dari kayu; lanjam dibuat dari kayu; lisung dibuat dari kayu; perah bedog dibuat dari kayu; rengkong dibuat dari kayu dan tali; singkal dibuat kayu; dan wiluku dibuat dari kayu.

Temuan tersebut memberi gambaran bahwa masyarakat petani di Kecamatan Sumur memiliki kreativitas dan keahlian tradisional dalam membuat alat-alat pertanian untuk memenuhi kebutuhan sendiri dengan memanfaatkan perangkat pengetahuan yang diwarisi turun-temurun dan bahan-bahan yang tersedia di lingkungan alam mereka, yakni kayu dan bambu. Hal itu sejalan dengan pendapat Suranny (2014: 47) bahwa alat pertanian tradisional dicirikan oleh bentuk yang sederhana dan penggerak yang berupa tenaga manusia. Sementara itu, alat pertanian modern penggeraknya adalah mesin. Sejak peradaban manusia mengenal budaya bercocok tanam, manusia sudah menunjukkan kreativitasnya dalam membuat alat pertanian.

Bentuk, fungsi, dan penamaan alat-alat pertanian tradisional akan bersesuaian dengan sumber daya lokal dan budaya yang dimiliki masyarakat sehingga menunjukkan kekhasan tersendiri. Menurut Farida (2017: 2), karena sistem mata pencarian berkarakteristik agraris, masyarakat Jawa memiliki perangkat peristilahan yang berelasi dengan unsur-unsur pertanian, termasuk istilahistilah yang secara spesifik berkaitan dengan teknologi pertanian. Oleh sebab itu, dapat dilihat pengaruh yang nyata terhadap peralatan tradisional yang digunakan. Dalam masyarakat tradisional, bahan-bahan dasar yang dipakai untuk membuat atau merakit peralatan untuk kebutuhan hidup sehari-hari mereka dilakukan dengan memanfaatkan potensi lingkungan alam sekitar, misalnya dalam pembuatan peralatan transportasi, pertanian, rumah tangga, dan pertukangan.

\section{Simpulan}

Berdasarkan hasil penelitian, ditemukan leksikon proses penggarapan sawah dalam lingkup budaya pertanian masyarakat Kecamatan Sumur berupa kata monomorfemis; kata polimorfemis hasil afiksasi yang melibatkan prefiks dan konfiks dan hasil reduplikasi; serta leksikon yang dibentuk dari gabungan dua kata. Leksikon proses setelah memanen padi berupa kata polimorfemis hasil afiksasi yang melibatkan prefiks dan konfiks; serta gabungan dua kata. Leksikon alat-alat pertanian berupa kata monomorfemis; kata polimorfemis hasil afiksasi yang melibatkan sufiks; dan leksikon yang dibentuk dari gabungan dua kata. 
Leksikon-leksikon ekoagraris yang ditemukan tersebut secara totalitas menunjukkan gambaran empiris terkait dengan karakteristik budaya masyarakat Kecamatan Sumur, khususnya dalam budaya bertani untuk memenuhi kebutuhan hidup mereka. Leksikon-leksikon tersebut menggambarkan tradisi dan kandungan nilai-nilai pengetahuan dan kearifan lokal setempat yang spesifik sehingga membedakannya dengan komunitas masyarakat petani lainnya di wilayah Provinsi Banten. Dalam dinamikanya setakat ini, tradisi pertanian sebagai perwujudan praktik budaya masyarakat di wilayah Kecamatan Sumur menunjukkan pergeseran karena terimbas oleh pengaruh transformasi pertanian modern sebagaimana tampak dalam leksikon proses bertani yang berhasil ditemukan.

\section{Daftar Pustaka}

Baehaqie, I. 2014. Jenang Mancawarna sebagai Simbol Multikulturalisme Masyarakat Jawa. Jurnal Komunitas, 180188.

https:/ / doi.org/10.15294/komunitas.v $6 \mathrm{i} 1.2953$

Budhiono, R. H. 2017. Leksikon Alat dan Aktivitas Bertanam Padi dalam Bahasa Jawa. Kandai, 235-248. https://doi.org/10.26499/jk.v13i2.210

Chang, W. 2001. Moral Lingkungan. Yogyakarta: Kanisius.

Crystal, D. 1985. A Dictionary of Language. Chicago: University of Chicago Press.

Dash, R. K. 2019. What is Ecolinguistics? Language in India, 379-384.

Derni, A. 2008. The Ecolinguistics Paradigm: An Integrationist Trend in Language
Study. The International Journal of Language Society and Culture, 21-30.

Farida, U. 2017. Istilah Peralatan Hidup Tradisional Masyarakat Jawa di Daerah Temanggung. Semarang: Balai Bahasa Jawa Tengah.

Fill, A. F., \& Muhlhausler. 2018. The Ecolinguistics Reader: Language, Ecology and Environment. London: Continuum.

Handoyo, E., \& Tijan. 2010. Model Pembelajaran Karakter Berbasis Konservasi: Pengalaman Universitas Negeri Semarang. Semarang: Universitas Negeri Semarang Press \& Widya karya.

Hidayati, N., \& Soeprobowati, T. R. 2017. Pertanian Ramah Lingkungan di Daerah Tangkapan Air Danau Rawapening. Proceeding Biology Education Conference (hlm. 126-130). Surakarta: UNS.

Juwitasari, W. C., \& Kristianto, Y. 2020, November). Bahasa dan Ekologi : Sebuah Perspektif Ekolinguistik dalam Pariwisata. Diambil kembali dari https:/ / repositori.unud.ac.id: https://repositori.unud.ac.id/protected /storage/upload/repositori/3ab459fcb9 abc4bc6210fe07cd6b9846.pdf

Kesuma, D., \& Nurlela, D. W. 2015. Keterancaman Leksikon Ekoagraris dalam Bahasa Angola/Mandailing: Kajian Ekolinguistik. Kajian Linguistik, 5476.

Kridalaksana, H. 2008. Kamus Linguistik. Jakarta: Gramedia.

Lestari, P. M., Irawati, R. P., \& Mujimin. 2019. Transformasi Alat Pertanian Tradisional ke Alat Pertanian Modern Berdasarkan 
Kearifan Lokal Masyarakat Jawa Tengah. Widyaparwa, 1-10. https:/ / doi.org/10.26499/wdprw.v47i 1.312

Ndruru, M. 2020. Leksikon Flora pada Bolanafo bagi Guyub Tutur Nias Kajian Ekolinguistik. Journal Education and Development, 257-260.

Nurhayati. 2010. Pengaruh Teknologi Mesin terhadap Perubahan Penggunaan Kosakata di Bidang Pertanian. Parole, 3447.

Nuzwaty. 2019. Pengenalan Awal Ekolinguistik. Medan: Sastra UISU Press.

Odum, E. P. 1996. Dasar-dasar Ekologi. Yogyakarta: Gadjah Mada University Press.

Prayitno, \& Arsyad. 2009. Petani Pedesaan dan Kemiskinan. Yogyakarta: Balai Pertanian Fakultas Ekonomi.

Sahril. 2020. Leksikon Ikan dalam Sampiran Pantun Melayu. Toto Buang, 149-163.

Santoso, T. 2018. Leksikon Ekologi Masyarakat Jawa dalam Paribasan Jawa: Kajian Ekolinguistik. Prosiding Seminar Nasional Kajian Bahasa, Sastra, dan Pengajarannya (SEMNAS KBSP) $V$ (hal. 378-383). Surakarta: Universitas Muhammadiyah Surakarta.

Sari, R. P. 2020. Berkebun Sayur Bersama Masyarakat Nias: Studi Ekolinguistik dari Sebuah Kepulauan. Dalam K. Nurwahyuni, \& S. Bulolo, Ekolinguistik: Analisis Kasus dan Penerapan Prinsip Dasar (hal. 40-56). Bali: Jayaprangus Press.
Sinaga, J., Simpen, I. W., \& Made, S. S. 2021. Khazanah Ekoleksikon Kedanauan dalam Guyub Tutur Bahasa Batak Toba. Kulturistik Jurnal Bahasa dan Budaya, 1-7. https://doi.org/10.22225/kulturistik.5 .1 .1976

Suktiningsih, W. 2016. Leksikon Fauna Masyarakat Sunda: Kajian Ekolinguistik. Retorika Jurnal Ilmu Bahasa, 142-160. https:/ / doi.org/10.22225/jr.2.1.54.142160

Suranny, L. E. 2014. Alat pertanian Tradisional sebagai Warisan Kekayaan Budaya Bangsa. Jurnal Arkeologi Papua, 45-55.

Susilo, R. K. 2008. Sosiologi Lingkungan. Jakarta: Raja Grafindo Persada.

Tualaka, D. 2016. Bentuk Khazanah Ekoleksikon Pertanian Bahasa Waijewa. Melanesia Jurnal Ilmiah Kajian Sastra dan Bahasa, 105-113. https:/ / doi.org/10.30862/jm.v1i1.742

Wahya, Fatimah, D., \& Citraresmana, E. 2017. Istilah Alat Teknologi Tradisional Pertanian Sawah Sunda Wuluku 'Bajak' dan Persebarannya Secara Geografis. Jurnal Sosioteknologi, 209-218. https:/ / doi.org/10.5614/sostek.itbj.20 17.16.2.6

Wahyuni, T. 2017. Makna Kultural pada Istilah Bidang Pertanian Padi di Desa Boja, Kabupaten Kendal, Jawa Tengah (Sebuah Tinjauan Etnolinguistik). Jalabahasa, 20-30. https://doi.org/10.36567/jalabahasa.v $13 \mathrm{i} 1.48$

Wisudariani, N. M. 2015. Khazanah Kosakata dan Pergeseran Kosakata dalam Sistem 
Pertanian Tradisional. Prosiding Seminar Nasional Riset Inovatif III (hlm. 106-111). Bali: Lembaga Penelitian Universitas Pendidikan Ganesha.
Yumiawan, T., Masrukhi, \& Alamsyah. 2014. Kajian Ekolinguistik Sikap Mahasiswa terhadap Pelestarian Lingkungan di Universitas Negeri Semarang. Indonesian Journal of Conservation, 41-49. 